\title{
The results of studies of eccentric tillage roller
}

\author{
Ivan Sharonov ${ }^{1, *}$, Vladimir Kurdyumov ${ }^{1}$ and Viktor Kurushin ${ }^{1}$ \\ ${ }^{1}$ Ulyanovsk State Agricultural University named after P. A. Stolypin, Ulyanovsk, RUSSIA
}

\begin{abstract}
Developed by eccentric tillage rink, which ensures the desired quality of the soil and increase the yield of crops. As a result of theoretical studies, an expression for determining the dynamic force that increases the intensity of crumbling soil lumps, depending on the regime parameters of the rink. In addition, the relationship between the power required when driving the rink, its parameters. The factors influencing the process of tillage by the developed roller are determined. As a criterion of optimization, the adopted coefficient of compliance with for the density soil of benchmark, which characterizes the quality of soil rolling from the position of compliance of soil density with agrotechnical requirements. As a result of experimental studies, the parameters and operating modes of the roller are optimized, at which the required quality of soil treatment is achieved.
\end{abstract}

Compaction of the soil is a necessary agricultural operation, have a positive impact on the yield of agricultural crops [1]. It is used in almost all soil and climatic zones to provide the required structure of the seedbed and improve seed contact with the soil, which is necessary to accelerate the flow of moisture to the seeds and emergence. Tillage rollers used in agricultural production, similar in nature to the impact on the soil, but different in design and functionality. Currently, the basis for improving the design of tillage rollers laid expansion of functionality through the introduction of the principles of impact on solid soil lumps stretching-compression of the soil and the imposition of vibration [2]. This allows for minimum operating costs to ensure the required quality of tillage and increase resistance to soil erosion, ensuring the principles of ecological farming. Reduction of operational and labor costs per unit of finished products can be provided by the use of tillage rollers in the combined units $[3,4]$. Therefore, it is important to improve the design of tools, taking into account the conditions of their operation and the requirements for the cultivation of various crops, as well as the rationale for the design parameters and modes of operation of the developed tools.

The purpose of the study is to improve the quality of surface tillage during sowing of grain crops and, as a result, increase their the yield.

The task of the study is to develop a tillage roller for tillage when sowing grain crops, which will provide the required quality of soil rolling.

Based on the analysis of the tillage rollers [2], in order to improve the crushing of soil lumps and the uniformity of the density of the field, we have created an innovative eccentric roller [5 - 8], which combines the advantages of different effects of its working bodies on the same areas of the soil surface. Roller (fig. 1) containing frame 1, mounted on

* Corresponding author: ivanshar2009@yandex.ru 
it one after another hollow cylinders 2 and 3 of equal diameter. Cylinders 2 and 3 mounted on frame 1 on axes 4 . On the axis 4 of cylinder 2 and 3 on the one hand mounted sprockets 5 are of equal diameter, connected by a chain 6 , the tension of which is regulated by the sprocket 7 . The axes 4 of cylinders 2 and 3 are eccentrically installed and displaced from the horizontal axes of the symmetry of the cylinders by the same distance, while the axis of the cylinder 2 is shifted from its horizontal axis of symmetry to the side opposite to the direction of displacement of the axis of the cylinder 3 . The frame 1 of the tillage roller is equipped with a trailed device 8 .

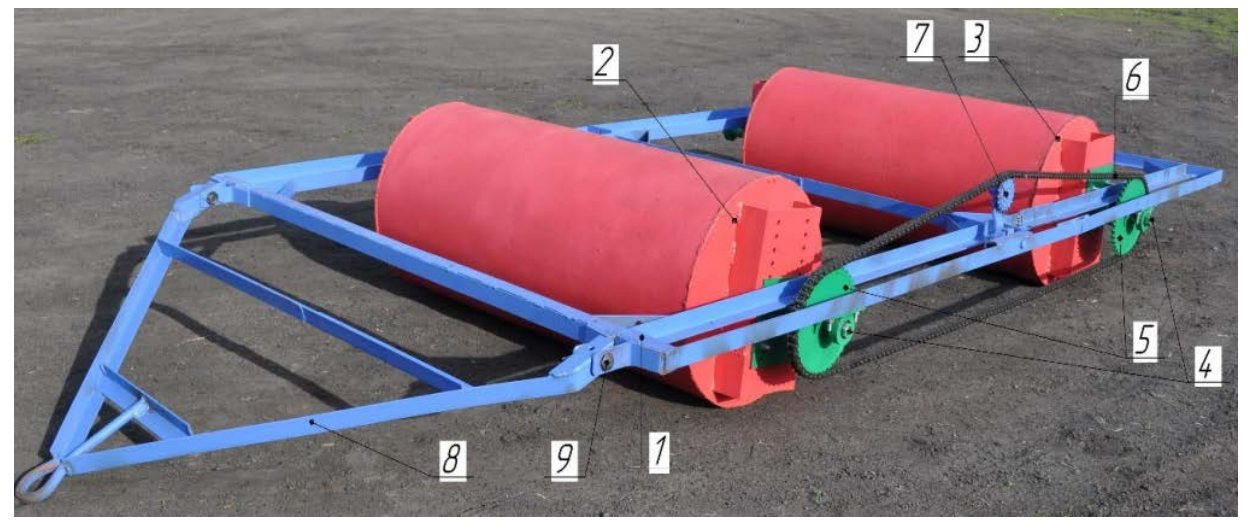

1 - frame; 2, 3 - hollow cylinders; 4 - axis of hollow cylinders; 5 - sprocket; 6 - roller chain; 7 - a tension sprocket; 8 - hitch; 9 - hinge

Fig. 1. Eccentric tillage roller.

Eccentric tillage roller works as follows. Pre-set hollow cylinders 2 and 3 so that the axis of the cylinder 2 was shifted from its horizontal axis of symmetry in the direction opposite to the direction of displacement of the axis of the cylinder 3 and in this position connect the sprockets 56 chain. When moving the tillage roller, hollow cylinders 2 and 3 begin to rotate, rolling the top soil layer. In this case, the eccentrically mounted part of the cylinder 2 with a large mass relative to the axis 4 is rolled over one section of the field surface, and the part of the cylinder 2 having a smaller mass is rolled over the next section of the field surface. Then, eccentrically installed relative to the axis 4 of the cylinder 3 , having a smaller mass, is rolled along the surface area of the field, which was previously treated by the part of the cylinder 2 having a large mass. Conversely, the mounted eccentrically relative to the axis 4 part of theof the cylinder 3, rolls over the area of the field surface, which was compacted by the part of the cylinder 2 having a smaller mass. At the same time, cylinders 2 and 3 eccentrically installed relative to their horizontal axes of symmetry provide more intensive crumbling of soil lumps. The displacement of the axis 4 of the cylinder 2 from its horizontal axis of symmetry in a direction opposite to the offset direction of the axis 4 of the cylinder 3 from its horizontal axis of symmetry allows to keep constant the density of the soil after the passage of the hollow cylinders 2 and 3 of the rink and to provide high quality compacting soil. At the same time, the intensity of crumbling of soil lumps with their increased hardness can be further increased by increasing the speed of the unit and the value of eccentricity.

The main advantage of the eccentric roller is that during its rolling on the soil surface, an additional dynamic force is created, which increases the degree of soil compaction and the intensity of destruction of soil lumps at the same weight of the roller.

In the course of the analytical study of the work eccentric rink was revealed the dependence of the dynamic forces of the mass of the roller, the eccentricity and the angular acceleration of hollow cylinder: 


$$
F_{d y n}=m_{f} e \varphi^{\prime \prime} / 6
$$

where $m_{f}$ - the mass of the roller frame with ballast, $\mathrm{kg}$; e - the eccentricity of the axis of the hollow cylinder, $\mathrm{m} ; \varphi^{\prime \prime}-$ the instantaneous angular acceleration of the roller cylinder, $\sec ^{-2}$.

The instantaneous angular acceleration of the roller cylinder

$$
\varphi^{\prime \prime}=\left(F_{f r} R+S_{x} e \cdot \cos \alpha-S_{y} e \cdot \sin \varphi\right) / m \rho^{2},
$$

where $F_{f r}$ - the friction force of the hollow cylinder on the soil, $\mathrm{H} ; R$ - the radius of the hollow cylinder, m; $S_{x}$ и $S_{y}$ - horizontal and vertical reactions of the hollow cylinder from the impact of the frame, respectively, $\mathrm{H} ; \varphi$ - the angle of rotation of the eccentrically mounted axis of the hollow cylinder of the roller relative to the vertical axis y, deg.; $\rho-$ radius of inertia of the hollow cylinder of the roller, $\mathrm{m} ; m$ - the mass of a hollow cylinder roller, $\mathrm{kg}$.

Taking into account expressions (2) and that $F_{f r}=f N=f g\left(m+0,5 m_{f}\right) ; S_{\mathrm{x}}=T=F_{f r}=$ $f g\left(m+0,5 m_{f}\right) ; S_{\mathrm{y}}=0,5 m_{f} g$ (where $T$ - thrust force, $\mathrm{H} ; f$ - coefficient of friction; $g$ - acceleration of free fall, $\mathrm{m} / \mathrm{sec}^{2}$ ), equation (1) takes the form:

$$
F_{d y n}=m_{f} e g\left\{\left[f\left(m+0,5 m_{f}\right)(R+e \cdot \cos \varphi)-0,5 m_{f} e \cdot \sin \varphi\right] / 6 m \rho^{2}\right\} .
$$

In assessing the operational parameters of the unit is an important indicator of the power $P$, spent on rolling the tillage roller on the field. This criterion determines the fuel consumption, which, as a result, affects the economic efficiency of tillage.

Power consumed for rolling the roller, $\mathrm{W}$ :

$$
P=d A / d t
$$

where $A$ - the work of the forces to move the tillage roller, $\mathrm{J} ; t$ - time, sec.

To determine the work done by the forces, we use the theorem on the change of kinetic energy in the differential form:

$$
d E_{\mathrm{K}}=\sum_{k} d A_{k}^{e}+\sum_{k} d A_{k}^{i}
$$

where $d E$ - kinetic energy of the system, $\mathrm{J} ; \sum_{k} d A_{k}^{e}, \sum_{k} d A_{k}^{i}$ - the sum of elementary works of external and internal forces of the system, J.

In steady-state operation, the speed of the tillage roller $v=$ const, hence the kinetic energy $d E_{\mathrm{k}}=0$. Hence, the sum of elementary works of internal forces $\sum_{k} d A_{k}^{e}=0$, a $\sum_{k} d A_{k}^{e} \neq 0$, therefore, the equation of the sum of elementary works of external forces write in the following form:

$$
\begin{gathered}
\sum_{k} d A_{k}^{e}=d A_{g r}+d A_{Q}+d A_{N 1}+d A_{N 2}+ \\
2 d A_{f r 1}+2 d A_{f r 2}+2 d A_{M 1}+2 d A_{M 2},
\end{gathered}
$$

where $d A_{g r}$ - elementary work of gravity, $\mathrm{J} ; d A_{Q}$ - elementary work of forces of aerodynamic resistance, $\mathrm{J} ; d A_{N 1}, d A_{N 2}$ - the elementary work of forces of normal reactions of the soil on the hollow cylinder, $\mathrm{J} ; d A_{f r 1}, d A_{f r 2}$ - the elementary work of the friction forces of the sliding hollow cylinder, $\mathrm{J} ; d A_{M 1}, d A_{M 2}$ - the elementary work of the forces of rolling friction, $\mathrm{J}$.

Since hollow cylinders are rolled on a horizontal surface, the vertical movement of the center of mass of the roller, to which the gravity of the roller is applied, is zero, so $d A_{g r}=0$. In the rolling hollow cylinder without slipping their instant centers of velocity $P_{\mathrm{j}}$ is applied 
at the points of tangency. The friction forces of the slide and normal reactions are applied at the same points, therefore $d A_{f r 1}=0, d A_{f r 2}=0$, as well as $d A_{N 1}=0, d A_{N 2}=0$.

Since the dimensions of the hollow cylinders of the roller are the same and the coefficients of friction of the rolling of the hollow cylinders on the soil are equal, the elementary work of the moments of friction of the rolling forces is determined for one cylinder, taking the normal reaction from the impact of the roller $N=N_{1}+N_{2}=m g$, where $N_{1}, N_{2}$ - the normal reaction of the soil against the impact of hollow cylinders

$$
d A_{M 1}+d A_{M 2}=-f N_{1} d \varphi-f N_{2} d \varphi=-f d \varphi\left(N_{1}+N_{2}\right)=-f m g d \varphi .
$$

The normal reaction forces work negatively, since the direction of the rolling friction torque is opposite to the direction of rotation of the hollow cylinders.

Elementary work of the drag force, $\mathrm{J}$ :

$$
d A_{Q}=-Q d s=-0,5 \mu \rho v^{2} S d s=-\mu \rho v^{2} R h d l,
$$

where $Q$ - aerodynamic drag force of the roller, $\mathrm{H} ; d l$ - the movement of the roller, $\mathrm{m} ; \mu-$ aerodynamic coefficient depending on the shape of the roller; $\rho$-air density, $\mathrm{kg} / \mathrm{m}^{3} ; v-$ speed of the roller relative to the air, $\mathrm{m} / \mathrm{s} ; S$ - cross-sectional area of hollow cylinder, $\mathrm{m}^{2} ; h$ - the width of the hollow cylinder, $\mathrm{m}$.

Taking into account formulas (5), (6), (7) and (8) the expression (4) takes the form:

$$
P=\left(\mu \rho v^{2} R h d l / d t\right)+(f m g d \varphi / d t)=\mu \rho v^{3} R h+f m g v / R .
$$

Expression (9) establishes the relationship of power P, required for rolling the roller, with its design parameters.

The process of soil treatment with an eccentric roller is influenced by many different factors, of which the following independent factors were chosen: $v$ - speed of the tillage roller, $\mathrm{km} / \mathrm{h} ; m_{b}$ - ballast weight of roller, $\mathrm{kg} ; e$ - eccentricity of the axis of the cylinders, $\mathrm{mm}$. As a criterion of optimization adopted coefficient of compliance with for the density soil of benchmark $k_{\rho}$, which characterizes the quality of tillage in terms of compliance with the density of the soil agrotechnical requirements [9]:

$$
k_{\rho}=0,01\left[1-\left(\left|\rho_{\text {opt }}-\rho_{m}\right| / \rho_{\text {opt }}\right)\right]
$$

where $\rho_{\text {opt }}$ - optimal soil density at the depth of seed placement, established in accordance with agricultural requirements, $\mathrm{kg} / \mathrm{m}^{3} ; \rho_{m}$ - measured soil density after the experiment [10], $\mathrm{kg} / \mathrm{m}^{3}$.

In full compliance with the density of the sowing layer of soil agrotechnical requirements $k_{\rho}=1$. After processing the results of the experiments, adequate mathematical models of the process of soil rolling by the tillage roller were obtained. The regression equation in the natural values of the factors characterizing the influence of $m_{b}$ and eccentricity $e$ on the coefficient $k_{\rho}$ :

$$
\begin{gathered}
k_{\rho}=0,8545-0,000006 e^{2}-0,000002 m_{b}{ }^{2}+ \\
+0,0009 e+0,0006 m_{b}-0,0000012 e m_{b}
\end{gathered}
$$

A graphical representation of the response surface and its two-dimensional cross-section is shown in figure 2. The regression and response surface equations from the interaction of other factors were obtained in a similar way.

After processing the results of experimental studies, it was found that after the passage of the proposed eccentric roller, the coefficient $k_{\rho}=0.99$ (this corresponds to $\rho=1211$ $\mathrm{kg} / \mathrm{m}^{3}$ ), which fully satisfies the agrotechnically specified limit $k_{\rho}=0.98 \ldots 1$, in which the 
density of the soil at the depth of seeding $\rho=1180 \ldots 1220 \mathrm{~kg} / \mathrm{m} 3$. This $k_{\rho}$ value is achieved at the speed $v=11.7 \mathrm{~km} / \mathrm{h}$, ballast weight $m_{b}=126 \mathrm{~kg}$ and eccentricity e $=61 \mathrm{~mm}$.
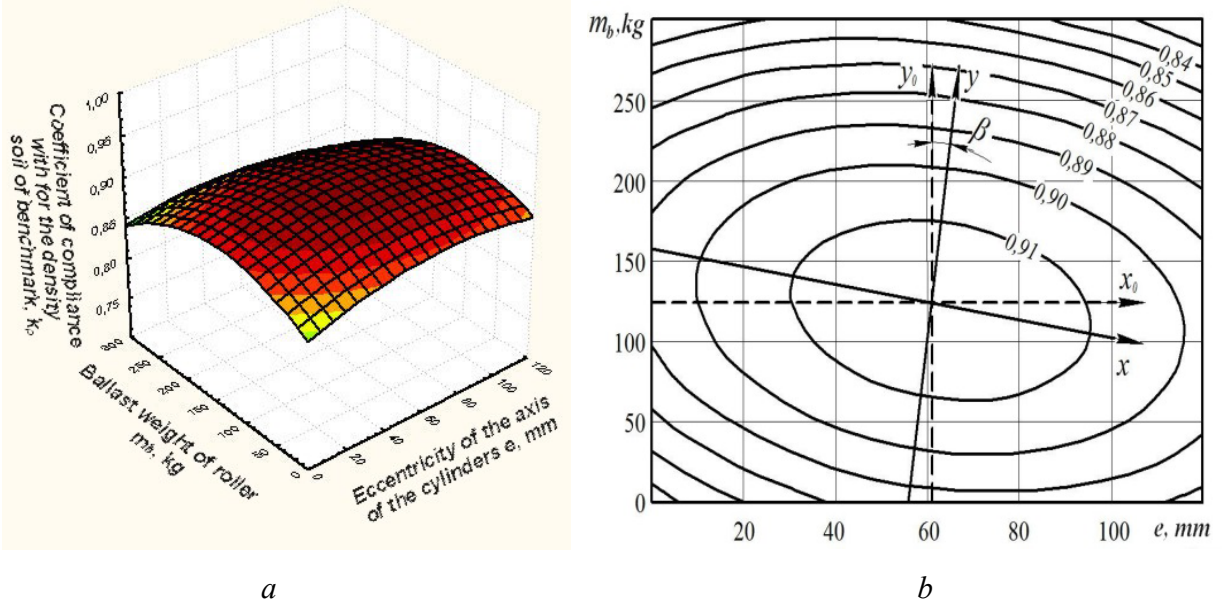

Fig. 2. The response surface $(a)$ and its two-dimensional cross-section $(b)$ from the interaction of the mass of the ballast $m_{b}$ and the eccentricity $e$ and their joint effect on the coefficient $k_{\rho}$

As a result of theoretical studies of the eccentric roller operation process, it was revealed that during its movement there is a dynamic force that increases the intensity of crumbling of soil lumps, provides the required compaction of the seed layer of the soil. Experimental studies of the eccentric roller allowed to determine its optimal parameters, in which the coefficient of compliance with the standard $k_{\rho}=0.99$, which is better than the ring-spur roller by $24 \%\left(k_{\rho}=0.75\right)$.

\section{Reference}

1. E. S. Zykin, V. I. Kurdyumov, I. A. Sharonov, Optimization of regime parameters of the roller-ridge-macker agent, Reports of the Russian Academy of agricultural Sciences, 2013, № 1, p. 58-60.

2. Y. A. Semenikhina, The analysis of rotating devices for leveling and soil compaction, Collection of scientific reports of the XVIII International scientific and practical conference, September 23-24, 2015, Tambov, 2015, 303 p.

3. N. E. Rudenko, K. D. Padalin, How to reduce energy costs and improve the quality indicators under continuous tillage, Vestnik APK Stavropol, 2014, № 1(13), pp. 66-68.

4. A.K. Subaeva, A.A. Zamaidinov, V.I. Kurdyumov, E.S. Zykin, Quality control indicators of soil ridges at sowing cultivated crops, International Journal of Pharmacy and Technology. - vol. 8, iss. 3, 2016, p. 14965-14972.

5. V. I. Kurdyumov, I. A. Sharonov, A. S. Egorov, Tool for soil rolling, Patent No. 2564486 Russian Federation, publ. 10/10/2015, bull. no. 28.

6. V. I. Kurdyumov, I. A. Sharonov, A. S. Egorov, Tool for soil rolling, Patent No. 2567207 Russian Federation, publ. 10.11.2015, byul. No. 31.

7. V. I. Kurdyumov, I. A. Sharonov, A. S. Egorov, Tool for soil rolling, Patent No. 2567208 Russian Federation, publ. 10.11.2015, byul. No. 31.

8. V. I. Kurdyumov, I. A. Sharonov, A. S. Egorov, Tool for soil rolling, Patent No. 152307 Russian Federation, publ. 20.05.2015, byul. No. 14. 
9. V. V. Kurushin, I. A. Sharonov, V. I. Kurdyumov, Determination of the design parameters of the roller-ridge-macker, Bulletin of the Ulyanovsk state agricultural Academy, 2015, № 3, p. 131-135.

10. V. I. Kurdyumov, E. S. Zykin, I. A. Sharonov, V. V. Kurushin, V. E. Proshkin, A. S. Egorov Device for determining soil density, Patent 149064 Russian Federation, publ. 20.12.2014, byul. No. 35 . 